\title{
DERECHO Y POLÍTICAS AMBIENTALES EN LA COMUNIDAD \\ VALENCIANA (SEGUNDO SEMESTRE 2016)
}

\author{
p. 1-5 \\ DRET I POLÍTIQUES AMBIENTALS A LA COMUNITAT VALENCIANA \\ (SEGON SEMESTRE 2016) \\ p. 6-9 \\ Marta Oller Rubert \\ Profesora contratada doctora de Derecho Administrativo/Professora contractada \\ doctora de Dret Administratiu
}

Universitat Jaume I

\begin{abstract}
Sumario: 1. Espacios naturales protegidos: Ley 7/2016, de 30 de septiembre, de reforma del artículo 15 de la Ley 11/1994, de 27 de diciembre, de la Generalitat, de Espacios Naturales Protegidos de la Comunitat Valenciana. 2. Gestión de residuos municipales: Decreto-Ley 4/2016, de 10 de junio, del Consell, por el que se establecen medidas urgentes para garantizar la gestión de residuos municipales. 3. Mesa forestal: Orden 11/2016, de 24 de mayo, de la Conselleria de Agricultura, Medio Ambiente, Cambio Climático y Desarrollo Rural, por la que se modifica la Orden 15/2013, de 25 de julio, de la Conselleria de Infraestructuras, Territorio y Medio Ambiente, por la que se regula la Mesa Forestal de la Comunitat Valenciana (DOCV 2/6/2016). 4. Caza: Orden 16/2016, de 13 de julio, de la Conselleria de Agricultura, Medio Ambiente, Cambio Climático y Desarrollo Rural, por la que se fijan, para la temporada 2016-2017, los períodos hábiles y normas de caza en las zonas comunes y se establecen otras regulaciones en los cotos de caza y zonas de caza controlada en la Comunitat Valenciana (DOCV 15/07/2016).
\end{abstract}

1. Espacios naturales protegidos: Ley 7/2016, de 30 de septiembre, de reforma del artículo 15 de la Ley 11/1994, de 27 de diciembre, de la Generalitat, de Espacios Naturales Protegidos de la Comunitat Valenciana

La modificación introducida por la Ley 7/2016 en la Ley 11/1994, de 27 de diciembre, de Espacios Naturales Protegidos de la Comunitat Valenciana, obedece al interés de dotar de la máxima protección, por su valor ecológico, a las zonas denominadas como "humedales", y que había sido objeto de restricción, pues en el año 2013 se modificó precisamente este artículo 15 , con el fin de incluir únicamente como zonas protegidas a 
aquellas que sí estuvieran debidamente catalogadas. En efecto, como la propia ley de modificación se encarga de destacar, diversas sentencias recientes del Tribunal Supremo habían fallado a favor de otorgar la máxima protección a los humedales, con independencia de su catalogación formal; en cambio, la redacción vigente hasta el año 2016 del reformado artículo 15, en el que se definen las “zonas húmedas”, obligaba a que, para considerarlas protegidas, estas zonas tenían que estar "debidamente catalogadas". Con la nueva redacción dicha obligación se ha eliminado, ampliándose así la protección otorgada a estas zonas

\section{Gestión de residuos municipales: Decreto-Ley 4/2016, de 10 de junio, del Consell, por el que se establecen medidas urgentes para garantizar la gestión de residuos municipales}

La urgencia y la necesidad de regular la gestión de los residuos municipales son los argumentos utilizados para justificar el uso del decreto-ley, una medida extraordinaria a través de la cual el Consell busca garantizar dicha gestión en el ámbito de la Comunidad Valenciana. Por esta razón, se han modificado la Ley 10/2000, de 12 de diciembre, de Residuos de la Comunitat Valenciana, y la normativa con rango legal que regula el régimen jurídico de la empresa pública VAERSA (Valenciana de Aprovechamiento Energético de Residuos, S. A.).

Las novedades son de calado pues se amplían las potestades de intervención de la Generalitat Valenciana en el caso de que los municipios incumplan sus obligaciones, como se contempla en el reformado artículo 6.5 de la citada Ley 10/2000, relativo a las competencias municipales. En efecto, en el artículo 6, donde se prevé la posibilidad de intervención de la conselleria competente, se enumeran como tales los supuestos de no prestación de servicios obligatorios, de incumplimiento de la ley y, como novedad, de incumplimiento de los planes autonómicos de residuos. Además, se prevé expresamente que, una vez que el órgano autonómico realice el requerimiento que insta al cumplimiento, el plazo del que disponen los municipios para ello sea de un mes, cuando el anterior plazo era de tres meses, trascurrido el cual la Generalitat procederá a adoptar las medidas necesarias a costa del ente incumplidor.

Asimismo, se incluye un nuevo párrafo en el apartado 5 que es especialmente conflictivo por cuanto supone una importante restricción a la autonomía local ya que permite, como 
medida excepcional, sustituir al municipio en la realización de los servicios de gestión durante un tiempo limitado, esto es, el estrictamente imprescindible. Para ello, se requieren una serie de garantías como el informe al Consell.

Otro de los preceptos afectados por el Decreto-Ley ha sido el artículo 8, relativo a las competencias de la Generalitat: en el apartado 7) se ha incluido la posibilidad de que los municipios realicen encomiendas de gestión a la Generalitat a través del oportuno convenio; y en el apartado 8), como complemento de la reforma del artículo 6.5, se contempla la posibilidad de prestar los servicios en el caso de sustitución o dispensa del artículo 6.6.

El artículo 36, incluido en el capítulo que regula la elaboración de los proyectos de gestión de residuos, modifica su tramitación, pues la convocatoria de concurso público para presentar proyectos de gestión alternativos solo tendrá lugar una vez que se haya admitido a trámite un proyecto de gestión privada, no como en la legislación anterior, cuando se presentaba un proyecto de gestión de iniciativa pública.

También resulta afectado por el Decreto-Ley el ámbito competencial de VAERSA, empresa pública dedicada a la prestación de servicios de gestión ambiental. En este sentido, en el artículo 4, apartado 2. ${ }^{\circ}$, de la Ley 12/2010, de 21 de julio, de la Generalitat, de medidas urgentes para agilizar el ejercicio de actividades productivas y la creación del empleo, se añade un párrafo cuarto que posibilita que VAERSA pueda ser también considerada medio propio y servicio técnico de los consorcios y otras entidades que integran la Administración local.

3. Mesa forestal: Orden 11/2016, de 24 de mayo, de la Conselleria de Agricultura, Medio Ambiente, Cambio Climático y Desarrollo Rural, por la que se modifica la Orden 15/2013, de 25 de julio, de la Conselleria de Infraestructuras, Territorio y Medio Ambiente, por la que se regula la Mesa Forestal de la Comunitat Valenciana (DOCV 2/6/2016)

La Mesa Forestal de la Comunitat Valenciana se creó en el año 2013 como órgano de participación, información y consulta de la conselleria competente en materia de medio ambiente, desarrollándose su estructura a través de la Orden 15/2013, de 25 de julio, de la Conselleria de Infraestructuras, Territorio y Medio Ambiente. No obstante, en el año 
2015 se produjeron cambios en la organización de la GVA que conllevaron que la nueva Conselleria de Agricultura, Medio Ambiente, Cambio Climático y Desarrollo Rural apostara por un mayor fomento de la participación y de la representación social en la Mesa Forestal. En este sentido, se modificó la composición de la Mesa para aumentar el número de representantes. Así, se introdujo un representante de la dirección general con competencias sobre prevención de incendios forestales y otro representante con competencias en extinción de incendios, mientras que el anterior representante con competencias en materia de agricultura fue sustituido por otro con competencias en medio rural. Asimismo, se incorporó a las personas titulares de las direcciones territoriales de Alicante, Castellón y Valencia de la conselleria con competencias en materia forestal y también a un representante de los agentes medioambientales de la Comunitat Valenciana; se aumentó a dos el número de representantes de ONG cuyo objeto sea la defensa del medio ambiente y también el de los representantes de entidades dedicadas a la investigación y formación forestal; y los representantes de las universidades de la Comunidad Valenciana pasaron a tres, especificándose que debe tratarse de universidades públicas y que debe haber un miembro por cada provincia, que son propuestos por el Consell Valencià d'Universitats. También se incluyó como nuevos miembros a dos representantes de colegios profesionales de la Comunidad Valenciana relacionados con el estudio y la gestión de los ecosistemas forestales, a dos representantes de las organizaciones sindicales agrarias más representativas $\mathrm{y}$, finalmente, a dos representantes de organizaciones sociales o sindicales agrarias, así como a dos representantes de entidades que promuevan el desarrollo rural. 
4. Caza: Orden 16/2016, de 13 de julio, de la Conselleria de Agricultura, Medio Ambiente, Cambio Climático y Desarrollo Rural, por la que se fijan, para la temporada 2016-2017, los períodos hábiles y normas de caza en las zonas comunes y se establecen otras regulaciones en los cotos de caza y zonas de caza controlada en la Comunitat Valenciana (DOCV 15/07/2016).

Como cada año, en julio se han aprobado los períodos hábiles y las normas de caza en el ámbito de la Comunidad Valenciana para la temporada 2016-2017 sobre la base del mandato de la Ley 13/2004, de 27 de diciembre, de Caza de la Comunitat Valenciana, con el fin de permitir la práctica de la caza en las zonas comunes y otras actividades, teniendo presente el principio de uso racional de los recursos cinegéticos. Además, la Orden también afecta a otras normas directamente relacionadas con ella en materia de diversas especies como el conejo de monte, la caza y el control del jabalí, la composición y el funcionamiento de la Comisión Valenciana de Homologación de Trofeos de Caza, o la orden que aprueba el plan de control de las poblaciones de arruí. 
Sumari: 1. Espais naturals protegits: Llei 7/2016, de 30 de setembre, de reforma de l'article 15 de la Llei 11/1994, de 27 de desembre, de la Generalitat, d'espais naturals protegits de la Comunitat Valenciana. 2.Gestió de residus municipals: Decret llei 4/2016, de 10 de juny, del Consell, pel qual s'estableixen mesures urgents per garantir la gestió de residus municipals. 3.Taula forestal: Ordre 11/2016, de 24 de maig, de la Conselleria d'Agricultura, Medi Ambient, Canvi Climàtic i Desenvolupament Rural, per la qual es modifica l'Ordre 15/2013, de 25 de juliol, de la Conselleria d'Infraestructures, Territori i Medi Ambient, per la qual es regula la Taula Forestal de la Comunitat Valenciana. 4.Caça: Ordre16/2016, de 13 de juliol, de la Conselleria d'Agricultura, Medi Ambient, Canvi Climàtic i Desenvolupament Rural, per la qual es fixen, per a la temporada 2016-2017, els períodes hàbils i normes de caça a les zones comunes i s'estableixen altres regulacions en els vedats de caça i zones de caça controlada a la Comunitat Valenciana.

\section{Espais naturals protegits: Llei 7/2016, de 30 de setembre, de reforma de l'article} 15 de la Llei 11/1994, de 27 de desembre, de la Generalitat, d'espais naturals protegits de la Comunitat Valenciana

La modificació introduïda per la Llei 7/2016 en la Llei 11/1994, de 27 de desembre, d'Espais Naturals Protegits de la Comunitat Valenciana, obeeix a l'interès de dotar de la màxima protecció, pel seu valor ecològic, a les zones denominades com a "aiguamolls", i que havia estat objecte de restricció, doncs l'any 2013 es va modificar precisament aquest article 15, amb la finalitat d'incloure únicament com a zones protegides a aquelles que sí estiguessin degudament catalogades. En efecte, com la pròpia llei de modificació s'encarrega de destacar, diverses sentències recents del Tribunal Suprem havien fallat a favor d'atorgar la màxima protecció als aiguamolls, amb independència de la seva catalogació formal; en canvi, la redacció vigent fins a l'any 2016 del reformat article 15, en el qual es defineixen les "zones humides", obligava al fet que, per considerar-les protegides, aquestes zones havien d'estar "degudament catalogades". Amb la nova redacció aquesta obligació s'ha eliminat, ampliant-se així la protecció atorgada a aquestes zones.

2. Gestió de residus municipals: Decret llei 4/2016, de 10 de juny, del Consell, pel qual s'estableixen mesures urgents per garantir la gestió de residus municipals

La urgència i la necessitat de regular la gestió dels residus municipals són els arguments utilitzats per justificar l'ús del decreto-llei, una mesura extraordinària a través de la qual el Consell busca garantir aquesta gestió en l'àmbit de la Comunitat Valenciana. Per aquesta raó, s'han modificat la Llei 10/2000, de 12 de desembre, de Residus de la Comunitat Valenciana, i la normativa amb rang legal que regula el règim jurídic de l'empresa pública VAERSA (Valenciana d'Aprofitament Energètic de Residus, S. a.). 
Les novetats són de calat doncs s'amplien les potestats d'intervenció de la Generalitat Valenciana en el cas que els municipis incompleixin les seves obligacions, com es contempla en el reformat article 6.5 de la citada Llei 10/2000, relatiu a les competències municipals. En efecte, en l'article 6, on es preveu la possibilitat d'intervenció de la conselleria competent, s'enumeren com a tals els supòsits de no prestació de serveis obligatoris, d'incompliment de la llei i, com a novetat, d'incompliment dels plans autonòmics de residus. A més, es preveu expressament que, una vegada que l'òrgan autonòmic realitzi el requeriment que insta al compliment, el termini del que disposen els municipis per a això sigui d'un mes, quan l'anterior termini era de tres mesos, transcorregut el qual la Generalitat procedirà a adoptar les mesures necessàries a costa de l'ens incomplidor.

Així mateix, s'inclou un nou paràgraf a l'apartat 5 que és especialment conflictiu puix que suposa una important restricció a l'autonomia local ja que permet, com a mesura excepcional, substituir al municipi en la realització dels serveis de gestió durant un temps limitat, això és, l'estrictament imprescindible. Per a això, es requereixen una sèrie de garanties com l'informe al Consell.Un altre dels preceptes afectats pel Decret-Llei ha estat l'article 8, relatiu a les competències de la Generalitat: a l'apartat 7) s'ha inclòs la possibilitat que els municipis realitzin encomanes de gestió a la Generalitat a través de l'oportú conveni; i a l'apartat 8), com a complement de la reforma de l'article 6.5, es contempla la possibilitat de prestar els serveis en el cas de substitució o dispensa de l'article 6.6.L'article 36, inclòs en el capítol que regula l'elaboració dels projectes de gestió de residus, modifica la seva tramitació, doncs la convocatòria de concurs públic per presentar projectes de gestió alternatius solament tindrà lloc una vegada que s'hagi admès a tràmit un projecte de gestió privada, no com en la legislació anterior, quan es presentava un projecte de gestió d'iniciativa pública.

També resulta afectat pel Decret-Llei l'àmbit competencial de VAERSA, empresa pública dedicada a la prestació de serveis de gestió ambiental. En aquest sentit, en l'article 4, apartat 2n., de la Llei 12/2010, de 21 de juliol, de la Generalitat, de mesures urgents per agilitar l'exercici d'activitats productives i la creació de l'ocupació, s'afegeix un paràgraf quart que possibilita que VAERSA pugui ser també considerada mitjà propi i servei tècnic dels consorcis i altres entitats que integren l'Administració local. 
3. Taula forestal: Ordre 11/2016, de 24 de maig, de la Conselleria d'Agricultura, Medi Ambient, Canvi Climàtic i Desenvolupament Rural, per la qual es modifica l'Ordre 15/2013, de 25 de juliol, de la Conselleria d'Infraestructures, Territori i Medi Ambient, per la qual es regula la Taula Forestal de la Comunitat Valenciana (DOCV 2/6/2016)

La Taula Forestal de la Comunitat Valenciana es va crear l'any 2013 com a òrgan de participació, informació i consulta de la conselleria competent en matèria de medi ambient, desenvolupant-se la seva estructura a través de l'Ordre 15/2013, de 25 de juliol, de la Conselleria d'Infraestructures, Territori i Medi ambient. No obstant això, l'any 2015 es van produir canvis en l'organització de la GVA que van comportar que la nova Conselleria d'Agricultura, Medi ambient, Canvi Climàtic i Desenvolupament Rural apostés per un major foment de la participació i de la representació social en la Taula Forestal. En aquest sentit, es va modificar la composició de la Taula per augmentar el nombre de representants. Així, es va introduir un representant de la direcció general amb competències sobre prevenció d'incendis forestals i un altre representant amb competències en extinció d'incendis, mentre que l'anterior representant amb competències en matèria d'agricultura va ser substituït per un altre amb competències al mig rural. Així mateix, es va incorporar a les persones titulars de les direccions territorials d'Alacant, Castelló i València de la conselleria amb competències en matèria forestal i també a un representant dels agents mediambientals de la Comunitat Valenciana; es va augmentar a dos el nombre de representants d'ONG l'objecte dels quals sigui la defensa del medi ambient i també el dels representants d'entitats dedicades a la recerca i formació forestal; i els representants de les universitats de la Comunitat Valenciana van passar a tres, especificant-se que ha de tractar-se d'universitats públiques i que ha d'haver-hi un membre per cada província, que són proposats pel Consell Valencià d’Universitats. També es va incloure com a nous membres a dos representants de col-legis professionals de la Comunitat Valenciana relacionats amb l'estudi i la gestió dels ecosistemes forestals, a dos representants de les organitzacions sindicals agràries més representatives i, finalment, a dos representants d'organitzacions socials o sindicals agràries, així com a dos representants d'entitats que promoguin el desenvolupament rural. 
4. Caça: Ordre 16/2016, de 13 de juliol, de la Conselleria d'Agricultura, Medi Ambient, Canvi Climàtic i Desenvolupament Rural, per la qual es fixen, per a la temporada 2016-2017, els períodes hàbils i normes de caça a les zones comunes $\mathbf{i}$ s'estableixen altres regulacions en els vedats de caça i zones de caça controlada a la Comunitat Valenciana (DOCV 15/07/2016)

Com cada any, al juliol s'han aprovat els períodes hàbils i les normes de caça en l'àmbit de la Comunitat Valenciana per a la temporada 2016-2017, basant-se en la Llei 13/2004, de 27 de desembre, de caça de la Comunitat Valenciana, amb la finalitat de permetre la pràctica de l'exercici de la caça a les zones comunes i altres activitats, tenint present el principi d'ús racional dels recursos cinegètics. A més d'això, l'ordre també afecta altres normes que s'hi relacionen directament pel que fa a diverses espècies com el conill de muntanya, la caça i el control del senglar, la composició i el funcionament de la Comissió Valenciana d'Homologació de Trofeus de Caça, o l'ordre que aprova el pla de control de les poblacions d'arruí. 